\title{
New Sendai Framework Strengthens Focus on Reducing Disaster Risk
}

\author{
Margareta Wahlström ${ }^{1}$
}

Published online: 24 June 2015

(c) The Author(s) 2015. This article is published with open access at Springerlink.com

The Sendai Framework for Disaster Risk Reduction 2015-2030 aims to protect lives, health, livelihoods, ecosystems, cultural heritage, and critical infrastructure from natural and human-caused hazards over the next 15 years. It seeks to bring about "the substantial reduction of disaster risk and losses in lives, livelihoods and health and in the economic, physical, social, cultural and environmental assets of persons, businesses, communities and countries" (UNISDR 2015, p. 6). To achieve this major ambition, the UN General Assembly has endorsed the Sendai Framework and its set of seven clear targets and four priorities for action, which were adopted by the UN Member States at the Third United Nations World Conference on Disaster Risk Reduction in Sendai, Japan, in March 2015.

The enthusiasm for the Sendai Framework in the AsiaPacific region is evidenced by the fact that Indonesia, Mongolia, Thailand, and Vietnam moved quickly to translate the text and made clear statements of their intent to revise their current strategies that are largely based on the Sendai Framework's predecessor, the Hyogo Framework for Action 2005-2015 (HFA). It is also encouraging that 17 countries participated in the first major international disaster risk reduction gathering post-Sendai-the International Strategy for Disaster Reduction Asia Partnership meeting held in Bangkok in early June 2015 to discuss regional implementation of the new Sendai Framework.

Margareta Wahlström

wahlstromm@un.org

1 United Nations Special Representative of the SecretaryGeneral (SRSG) for Disaster Risk Reduction, United Nations International Strategy for Disaster Reduction (UNISDR), http://www.unisdr.org/
Indonesia, which has long been a champion of disaster risk reduction across the region and the world, has outlined its road map for implementation and is paying particular attention to how the Sendai Framework can support disaster risk management at the local level with a peoplecentered approach.

The Sendai Framework calls for a historic shift from an emphasis on disaster management to addressing disaster risk management. It focuses on the underlying drivers of disaster risk, such as poorly planned urban growth in areas subject to flooding, landslides, earthquakes, cyclones, and the effects of climate change. As the Sendai Framework states, "It is urgent and critical to anticipate, plan for and reduce disaster risk in order to more effectively protect persons, communities and countries" (UNISDR 2015, p. 4). This need encompasses smaller-scale as well as larger-scale hazards. It also includes slow-onset hazards, such as droughts, as well as sudden-onset events, such as earthquakes.

In addition to the reduction of disaster risk as an expected outcome, the Sendai Framework's goal is to prevent new risk, reduce existing risk, and strengthen societal and environmental resilience. There is also a set of guiding principles, including the primary responsibility of states to prevent and reduce disaster risk, and an emphasis on the engagement of all-of-society and all-state institutions. The scope of disaster risk reduction has been broadened significantly to focus on both natural and human-caused hazards and related environmental, technological, and biological hazards and risks. Health resilience is strongly promoted throughout.

There is also clear recognition of the global and regional platforms for disaster risk reduction as mechanisms for coherence across agendas, monitoring, and periodic 
reviews in support of UN Governance bodies. Sendai builds on the achievements of the Hyogo Framework for Action 2005-2015. It champions an approach that is people centered and preventive, and promotes the proactive management of disaster risk over the reactive management of disasters. The Sendai Framework outlines seven global targets:

- a substantial reduction in global disaster mortality;

- a substantial reduction in numbers of affected people;

- a reduction in economic losses in relation to global GDP;

- a substantial reduction in disaster damage to critical infrastructure and disruption of basic services, including health and education facilities;

- an increase in the number of countries with national and local disaster risk reduction strategies by 2020 ;

- enhanced international cooperation for developing countries; and

- increased access to multi-hazard early warning systems and disaster risk information and assessments.

Implementation of the Sendai Framework for Disaster Risk Reduction requires strong commitment and political leadership both at national and local levels. This is essential to ensure stronger risk governance and capable institutions that can take the lead and mobilize and motivate stakeholders. A key outcome of the 15-year strategy must be the development of communities that are not only risk informed but also knowledgeable about risk, and therefore understand how to eliminate or mitigate underlying drivers of risk and how to build back better after a disaster.

A critical concern for Asia in disaster risk management must be the scale and rapidity with which urbanization is taking place. Already more than half of the world's population lives in urban areas and one in three of the world's total population lives in cities and towns in low- and middle-income countries. One billion people live in slums or informal settlements and are exposed to a wide range of urban risks stemming from natural hazards, diseases, and inadequate support services. Urbanization and rapid population growth lead to the concentration of population and assets in hazard-prone urban areas. When a natural or human-caused hazard impacts exposed urban areas, this can combine with vulnerability created by poverty, population density, general living conditions, and lack of preparedness to worsen the impact of the disaster event.

In response to this critical need, the Sendai Framework urges a focus on four priority areas for action if we are to succeed in bringing about substantial reductions in loss of life, economic losses, and the numbers of people affected by disasters in cities and elsewhere:

- First, disaster risk management needs to be based on an understanding of disaster risk in all its dimensions of vulnerability, capacity, exposure of persons and assets, hazard characteristics, and the environment. Local government officials need to be given adequate training.

- Second, work is required to guide, encourage, and incentivize the public and private sectors to take action and address disaster risk.

- Third, public and private investment in disaster risk reduction needs to focus on structural and nonstructural measures that can also result in cobenefits such as economic growth and job creation. Target areas include early warning systems, protection of productive assets, and improved safety and functionality of critical infrastructure.

- The final priority is to strengthen disaster preparedness for more effective response. Disasters have demonstrated that the recovery, rehabilitation, and reconstruction phases are opportunities to build back better in a disaster-proof way.

The Sendai Framework is integral to upcoming major processes to mitigate and adapt to climate change and to agree to a new set of sustainable development goals. A growing political will to prevent and reduce disaster risk can also be seen in the commitment to develop global indicators so that progress towards the ambitious goals of the Sendai Framework for Disaster Risk Reduction can be measured.

Open Access This article is distributed under the terms of the Creative Commons Attribution 4.0 International License (http:// creativecommons.org/licenses/by/4.0/), which permits unrestricted use, distribution, and reproduction in any medium, provided you give appropriate credit to the original author(s) and the source, provide a link to the Creative Commons license, and indicate if changes were made.

\section{Reference}

UNISDR (United Nations International Strategy for Disaster Reduction). 2015. Sendai framework for disaster risk reduction 20152030. http://www.wcdrr.org/uploads/Sendai_Framework_for Disaster_Risk_Reduction_2015-2030.pdf. Accessed 6 Jun 2015. 